\title{
Propuesta de zonificación en base al crecimiento urbano de la ciudad de Piribebuy, Paraguay, comprendido entre 1994 y $2010^{*}$
}

\author{
Nestor D. Cabral Antúnez**
}

Recibido el 8 de julio de 2014; aceptado el 15 de julio de 2014

\begin{abstract}
As many other cities of the country, the City of Piribebuy has a deficit in urban and regional planning. For this reason an increasing haphazard urbanization causes various severe problems. Based on the urban development of Piribebuy City during 1994 and 2010 a descriptive study has been carried out, e.g. by identifying the commercial sector as well as the current land use, in order to create proposals for the future zonal development of the city. The study consists of three categories as there are: 1) the natural physical environment, describing the natural physical characteristics of the urban area (morphological analysis, elevation and slope of the ground, climate, soils, geology, hydrogeology, hydrology and vegetation) and of the Piribebuy Creek watershed; 2) the artificial physical environment, describing and quantifying the characteristics of the urban area (land use, infrastructure, roads, recreation areas; and historical districts); 3 ) the social environment, describing the demographical and economical development as well as the tourism on nature. This category was assisted by direct observations, interviews and photographical material. Two zones have been identified by the study: the first so-called urban zone (central, urbanized and peripherical) and the second zone, the complementary areas (environmental interest, environmental protection, touristic and historical sites and urban expansion), all with their own corresponding regulations and restrictions, in order to prevent their own to loose its special characteristics that make it unique.
\end{abstract}

Palabras clave: Urban processes; Mapping, Zoning, GIS.

* Trabajo publicado en el Segundo Simposio Paraguayo de Manejo y Conservación de Suelos, 25 y 26 de agosto de 2011, San Lorenzo, Paraguay.

** Profesor, ingeniero, geoógrafo, Maestro en Ciencias, docente de la Facultad de Ingeniería de la Universidad Nacional de Asunción, Paraguay, correo electrónico: cabralnestor@gmail.com 


\section{Resumo}

A cidade de Piribebuy assim como a maioria das cidades do país carecem de um ordenamento territorial. Em conseqüência disso, a expansão descontrolada e desordenada dos assentamentos humanos e a expansão não planejada está causando sérios problemas. Com o objetivo de realizar a proposta de zoneamento com base no crescimento urbano da cidade de Piribebuy, entre 1994 e 2010 e identificar os tipos de empreendimentos encontrados na área de estudo através do uso do solo atual foi realizado um estudo descritivo e aplicativo que consiste em três fases, 1) ambiente físico natural descrevendo as características físicas naturais da cidade (análise morfométrica, altimetria, clima, solo, geologia, hidrogeologia, hidrologia, declividade e vegetação), considerando como marco de gestão a bacia hidrográfica do Rio Piribebuy; 2) ambiente físico artificial descrevendo e quantificando as características da cidade (uso do solo, infraestrutura, rodovias, áreas de lazer) e, finalmente, 3) ambiente social que descreve os aspectos demográficos; atividades econômicas; turismo e natureza; bairros históricos onde se realizaram as entrevistas, observação direta e uso de registro fotográfico. Foram identificadas duas zonas; a primeira corresponde à chamada zona urbana (central, urbanizada e periférica) e, a segunda, chamada de área complementar (interesse ambiental, proteção ambiental, turismo/história e expansão urbana), todas com seus respectivos regulamentos relativos aos usos permitidos e não permitido, de modo a se evitar que a cidade perca as características que a tornam única.

Palavras-chave: procesos urbanos, mapeamento, zoneamento, GIS.

\section{Resumen}

La ciudad de Piribebuy, así como la mayoría de las ciudades del país carecen de un ordenamiento territorial. En consecuencia, la expansión incontrolada y desordenada de los asentamientos humanos y la ampliación no planificada está causando graves problemas. Con el objetivo de realizar la propuesta de zonificación en base al crecimiento urbano de la ciudad de Piribebuy comprendido entre 1994 y 2010 e identificar los tipos de emprendimientos encontrados en la zona de estudio a través del uso del suelo actual, fue realizado un estudio de tipo descriptivo y aplicativo que constó de tres fases, 1) medio físico natural describiendo las características físico naturales del casco urbano (análisis morfométrico, altimetría, clima, suelos, geología, hidrogeología, hidrología, pendiente y vegetación) considerando como marco de gestión la cuenca del arroyo Piribebuy; 2) medio físico artificial describiendo y cuantificando las características del casco urbano (usos del suelo, infraestructura, vialidad, espacios recreativos) y 3) medio social describiendo los aspectos demográficos, actividades 
económicas, turismo y naturaleza, cascos históricos para lo cual se realizaron entrevistas, observación directa y uso de registro fotográfico. Se identificaron dos zonas: la primera corresponde a la llamada zona urbana (central, urbanizada y periférica) y la segunda, denominada áreas complementarias (interés ambiental, protección ambiental, turística/histórica y expansión urbana), todas con sus correspondientes reglamentaciones referentes a usos permitidos, permisibles y no permitidos, a fin de evitar que el casco urbano pierda las características que lo hacen peculiar.

Palabras clave: procesos urbanos; cartografia, zonificación, SIG.

\section{Introducción}

La ciudad es percibida como algo caótico e incomprensible; sin embargo si se aborda como un sistema, cuyos componentes interactúan entre sí, su funcionamiento comienza a tener lógica, ya que la estructura urbana es el resultado de las actividades económicas, culturales y de los procesos sociales que ocurren en un espacio y tiempo determinados. La presente investigación parte de ese principio, se presenta el contexto urbano y los factores determinantes en los procesos de estructuración que han ocurrido en el Municipio de Piribebuy a lo largo de cerca de dos siglos, y específicamente, en los últimos 16 años. Cada etapa de su desarrollo ha sido marcada por fenómenos sociales, económicos, políticos, etc., que se han reflejado directamente en su estructura urbana. Estos fenómenos han determinado la orientación funcional, misma que puede ser presentada como una localidad independiente, histórica, turística, residencial, y en menor grado como centro de servicios. Además de ser una ciudad con valores arraigados tanto culturales como históricos, posee una invaluable riqueza desde el punto de vista paisajístico. Actualmente la zona natural y los espacios abiertos están dispersos en el casco urbano; los arroyos que dan carácter e identidad al municipio, están contaminados y no existe un proceso de crecimiento urbano apoyado en un plan de desarrollo, lo que conllevará a la extinción de aquellos espacios generadores de vida natural, urbana y social. Dicho municipio, carece de ordenamiento del territorio. En consecuencia, la expansión incontrolada y desordenada de los asentamientos humanos y la ampliación no planificada está causando graves problemas. En base a esto se plantea, como objetivo general, realizar una propuesta de zonificación en base al crecimiento urbano de la ciudad de Piribebuy comprendido entre 1994 y 2010.

\section{Material y métodos}

El estudio fue realizado en el casco urbano del Municipio de Piribebuy (Figura 1), situada en el Departamento de Cordillera, en dirección SE de Asunción a 74km de la misma. Actualmente, está compuesta por un total de seis barrios y para identificarlos 
se utilizó la cartografía digital de la Dirección General de Estadísticas, Encuestas y Censos. ${ }^{1}$ El tipo de investigación fue descriptivo, con enfoque mixto (cuantitativo y cualitativo).

Las técnicas e instrumentos para la recolección de los datos constaron de tres fases. En la fase documental se recopiló información referente a leyes, ordenanzas, estudios para el plan de desarrollo urbano local del municipio y planos respectivos. En la fase de campo se realizaron entrevistas y observaciones, y para la fase de análisis de información se tuvieron en cuenta como parámetros los siguientes puntos:

- Medio físico natural: análisis morfométrico, altimetría, clima, edafología, geología, hidrogeología, hidrología, pendiente y vegetación, considerando como marco de gestión la cuenca del arroyo Piribebuy.

- Medio físico artificial: usos del suelo, infraestructura, viabilidad y espacios recreativos.

- Medio social: descripción de los aspectos demográficos, actividades económicas, turismo y naturaleza, cascos históricos de Piribebuy.

Para la recolección de datos primarios se realizó observación in situ con levantamiento piloto y posterior modificación en gabinete, con acompañamiento de planos barriales con las manzanas. Partiendo de la tipología de usos del suelo se determinaron los elementos más relevantes a levantar de cada inmueble, datos que sirvieron para reconstruir la estructura urbana e identificar sus transformaciones. También se utilizaron fotografías para describir prácticas cotidianas, aspectos ligados a la cultura poblacional e indicadores relativos del lugar. Se han realizado entrevistas abiertas a personas ligadas a la municipalidad, pobladores y profesionales que habitan el área de estudio.

La recolección de la información secundaria se hizo a través de recopilación de información de libros, revistas, documentos y diversas publicaciones referentes a la zona de estudio y a la problemática detectada para la elaboración del marco teórico.

Para el procesamiento y análisis de datos se observaron indicios de procesos urbanos, algunos de los cuales pueden ser interpretados a partir de la información obtenida de fuentes primarias como los archivos de la municipalidad o del Servicio Nacional de Catastro, ${ }^{2}$ cartografía, fotografías aéreas de diferentes épocas e imágenes satelitales actuales. Durante el análisis se recopiló información sobre los factores físico-ambientales y sociales de la zona, a través de la cartografía elaborada por la Dirección del Servicio Geográfico Militar (DISERGEMIL) e información proporcionada por el municipio. 
Se elaboró un plano base con ayuda de ortofotocartas del SNC del año 1994 a escala 1:25,000 (MN44) y a escala 1:5,000 (MNPV, MNRV y MNPW) ${ }^{3}$, donde se delimitó el área de estudio. Los usos del suelo se determinaron mediante observaciones cartográficas, con imagen satelital Ikonos de $1 \mathrm{~m}$ de resolución espacial y levantamiento de los datos en campo, a través de un equipo receptor de señales satelitales GPS. Se dividió la región correspondiente a la zona urbana en territorios de diferentes usos, para ordenar el crecimiento de la misma y proteger los intereses de la comunidad, considerando sus potencialidades (Proyecto Ordenamiento Ambiental de Zonas Urbanas $).{ }^{4}$ Para el análisis de la información reunida y seleccionada se procedió a migrar los datos al programa ArcGIS ArcView (v9.3).
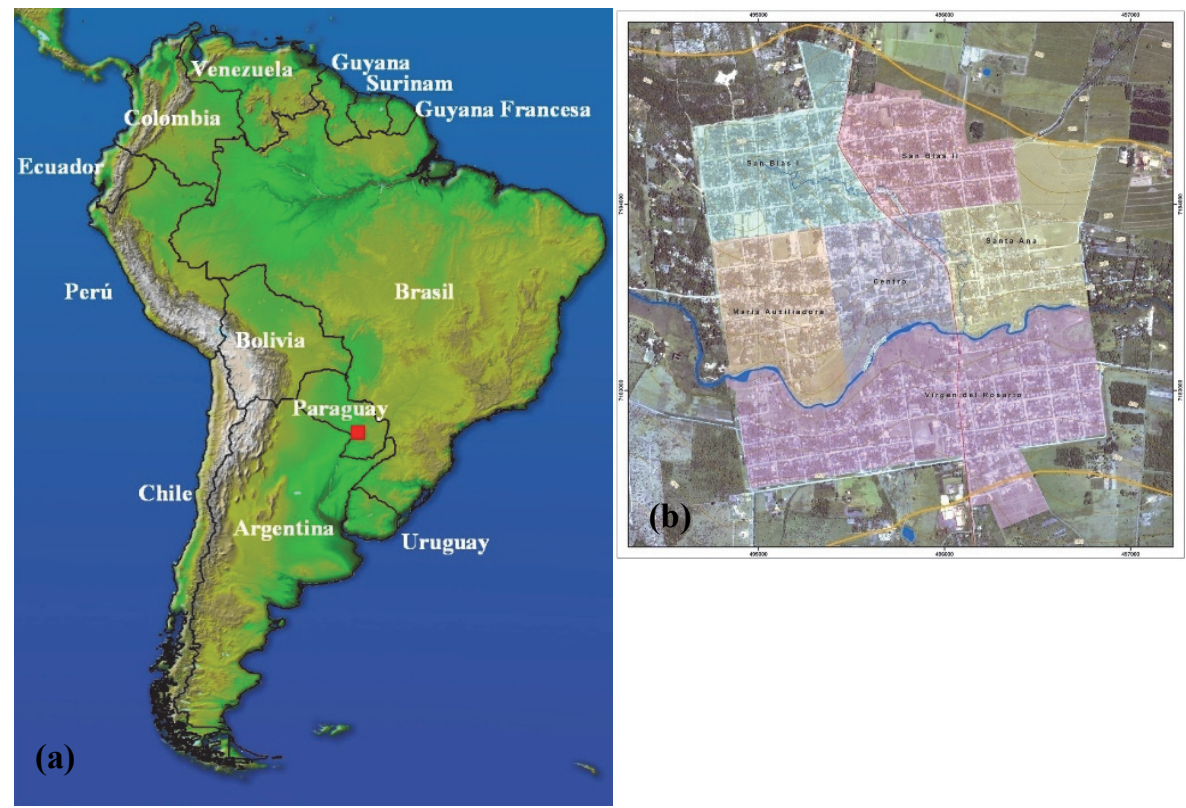

Figura 1. Ubicación del Municipio de Piribebuy a) Situado en el continente sudamericano b) Casco urbano del municipio.

3 Corresponden a la codificación establecida por la Dirección del Servicio Geográfico Militar (DISERGEMIL) para las ortofotocartas a escala: 1:5,000.

4 ORDAZUR, Zonificación básica del Centro Urbano del Distrito de Benjamín Aceval, Secretaría del Ambiente-Instituto Federal de Geociencias y Recursos Naturales, 2010, 69 pp. 


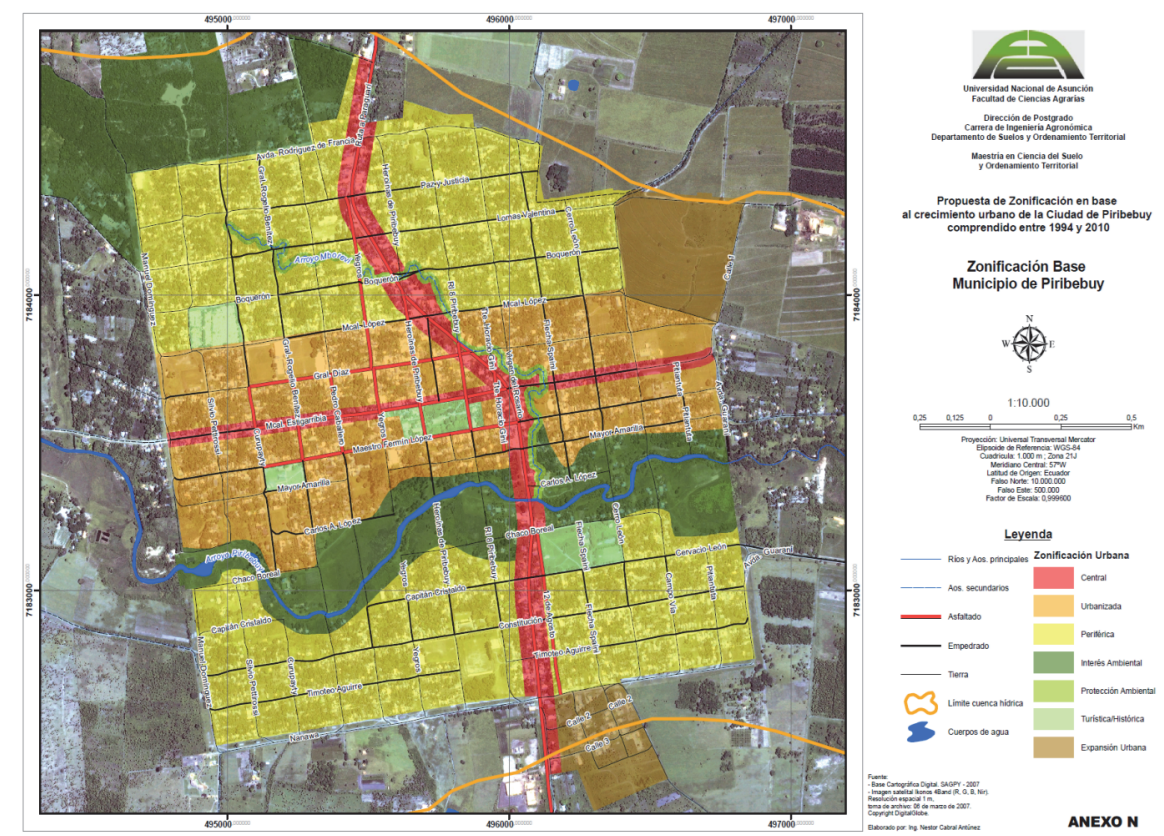

Figura 2. Propuesta de zonificación base del Municipio de Piribebuy.

\section{Resultados y discusión}

Según el Instituto Nacional de Ecología (INE), ${ }^{5}$ la cuenca del arroyo Piribebuy posee más de $90 \mathrm{~km}^{2}$, con poco desnivel, su cabecera posee la mayor altitud de la región (410msnm) y su salida hacia el arroyo Zanja Pyta posse $110 \mathrm{msnm}$, en una distancia de $23 \mathrm{~km}$. No se observa gran variación climática ni ecológica. En cuanto al orden de la red de drenaje posee control estructural débil, poca energía y poca erosión.

El coeficiente de compacidad de la cuenca es de 0.03 con forma redonda a oval redonda, por lo tanto en la cuenca tarda más en llegar la onda de crecida a la desembocadura, pero al mismo tiempo es más acusado el caudal punta, las características morfométricas no intensifican el vigor de las crecidas en la desembocadura, pero al mismo tiempo, más acusada y súbita es la misma crecida, y por tanto más alto el riesgo de inundaciones.

En la estación cálida del año predominan vientos húmedos proviniendo del noreste, por su parte, la estación fresca es caracterizada por vientos del sudeste o Sur estos traen, predominantemente, masas de aire polar de la Antártida. En el periodo de cambio de estaciones, las temperaturas pueden caer bruscamente en corto plazo del

5 INE, Análisis morfométrico de cuencas: caso estudio del parque Nacional Pico de Tancítaro, Instituto Nacional de Ecología, Dirección General de Investigación de Ordenamiento Ecológico y Conservación de Ecosistemas, México, 2004. 
día con un gradiente oeste-este. El ciclo anual de la lluvia, con máximos, durante los meses estivales y mínimos, en los invernales. La precipitación media anual es de 1,600mm (Carvallo, 2010). ${ }^{6}$

Según López et al., ${ }^{7}$ la cuenca del arroyo Piribebuy contiene 39.3\% de Rhodic Paleudult, y éste orden de suelo se encuentra totalmente dentro del casco urbano de Piribebuy; 10.3\% de Aquic Paleudalf; 3.1\% de Ruptic Alfic Eutrochrept; 36.2\% Lithic Quartzipsamment y 11.1\% de Lithic Udorthent.

La geología está representada por la formación Tobatí, secuencia superior del Grupo Caacupé, constituida principalmente por areniscas cuarzosas, frecuentemente con feldespato caolinizado, posee granulometría media a fina, siendo más grosera en el nivel inferior, presentan coloración blanca a rojiza con gran friabilidad. Se encuentran en parte silicificadas en zonas afectadas por fallas o por intrusiones ígneas de edad cretácica.

Hidrogeológicamente se encuentra asentada sobre el acuífero Caacupé y es la fuente de abastecimiento local. Según Ayala (2010), ${ }^{8}$ este acuífero es uno de los más importantes del país en calidad y cantidad, debido a las características sedimentarias de porosidad y permeabilidad. Debido al origen o fuente de sedimentación; un potente depósito de rocas siliciclásticas del tipo arenosa del grupo Caacupé, que hacen un filtro natural que asegura su potencial como recurso hídrico en el área. La hidrología superficial posee en el casco urbano el cauce más importante, el arroyo Piribebuy que lo atraviesa de oeste a este, mientras que el arroyo Mboreví lo atraviesa en dirección noroeste a sureste.

La pendiente del casco urbano de Piribebuy es de aproximadamente 3\%. La característica de la misma hace que la erosión sea media, posee drenaje fácil, sin problemas de drenaje natural, no presenta problemas a las vialidades ni a la construcción de obra civil. Bazant, ${ }^{9}$ recomienda como usos en el rango de pendiente (0-10\%) zona urbana de mediana y alta densidad, zonas de recarga acuífera, recreación, autopista y agrícola.

El casco urbano todavía cuenta con bosque nativo ribereño, al noroeste de la misma y limita con el barrio San Blás I. En el área de estudio las principales especies encontradas son: Ka’a Ovetí (Gluchea divaricata); Ñuãti Arroyo (Sebastina spp); Yvyra Pi'u Guasú (Ruprechtia laxifolia); Yaguarata'y (Cupania vernalis); Uruku'ra o Sangre de Dragón (Crotón urucurana), Yvyra Pytã (Peltophorum dubiun); Ka’a

6 Carvallo, F., Evaluación de recursos hídricos subterráneos para el desarrollo sostenible del norte y centro de Departamento de Cordillera, República del Paraguay, Universidad Autónoma de Asunción, Paraguay, 2010.

7 López Gorostiaga, O. et al., Estudio de reconocimiento de suelos, capacidad de uso de la tierra y propuesta de ordenamiento territorial preliminar de la Región Oriental del Paraguay, MAG, Asunción, Paraguay, 1995.

8 Ayala, M., Impacto Socio-ambiental en la subcuenca del arroyo Mboreví, afluente de la cuenca del arroyo Piribebuy, Universidad Autónoma de Asunción, Paraguay, 2010.

9 Bazant, J., Manual de diseño urbano, Editorial Trillas, 5a. edición, México, 1998. 


\section{Cuadro 1}

Usos permitidos, permisibles y no permitidos en la zonificación propuesta del casco urbano

\begin{tabular}{|c|c|c|c|c|}
\hline \multirow{4}{*}{ 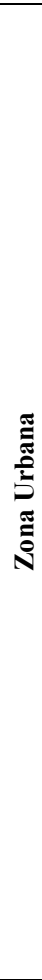 } & Zona & $\begin{array}{c}\text { Usos } \\
\text { permitidos }\end{array}$ & $\begin{array}{c}\text { Usos } \\
\text { permisibles }\end{array}$ & $\begin{array}{c}\text { Usos no } \\
\text { permitidos }\end{array}$ \\
\hline & Central & $\begin{array}{l}\text { - Viviendas de todo tipo } \\
\text { - Comercios/servicios: } \\
\text { vecinales, barriales } \\
\text { - Industrias inocuas: } \\
\text { pequeña y mediana } \\
\text { escala } \\
\text { - Equipamiento } \\
\text { comunitario: pequeña y } \\
\text { mediana escala } \\
\text { - Depósitos: pequeña y } \\
\text { mediana escala } \\
\text { - Servicios de } \\
\text { - esparcimiento }\end{array}$ & $\begin{array}{l}\text { - Comercios/servicios } \\
\text { zonales } \\
\text { - Industrias incómodas: } \\
\text { pequeña y mediana } \\
\text { escala } \\
\text { - Equipamiento } \\
\text { comunitario: gran escala } \\
\text { (compatible con la zona } \\
\text { urbana) } \\
\text { - Depósitos: gran escala }\end{array}$ & $\begin{array}{l}\text { - Industrias no } \\
\text { especificadas en } \\
\text { usos permitidos o } \\
\text { permisibles } \\
\text { - Usos no } \\
\text { - especificados } \\
\text { como permitidos o } \\
\text { permisibles }\end{array}$ \\
\hline & Urbanizada & $\begin{array}{l}\text { - Viviendas de todo tipo } \\
\text { - Conjuntos } \\
\text { - habitacionales } \\
\text { - Comercios/servicios: } \\
\text { vecinales, barriales } \\
\text { - Equipamiento } \\
\text { comunitario: pequeña } \\
\text { escala }\end{array}$ & $\begin{array}{l}\text { - Industrias inocuas: } \\
\text { pequeña escala } \\
\text { - Equipamiento } \\
\text { comunitario: mediana } \\
\text { escala } \\
\text { - Huertas familiares }\end{array}$ & $\begin{array}{l}\text { - Industrias no } \\
\text { especificadas en } \\
\text { usos permitidos o } \\
\text { permisibles } \\
\text { - usos no } \\
\text { especificados } \\
\text { como permitidos o } \\
\text { permisibles }\end{array}$ \\
\hline & Periférica & $\begin{array}{l}\text { - Viviendas unifamiliares } \\
\text { - Comercios/servicios } \\
\text { vecinales } \\
\text { - Equipamiento } \\
\text { comunitario: pequeña } \\
\text { escala } \\
\text { - Huertas familiares }\end{array}$ & $\begin{array}{l}\text { - Comercios/servicios } \\
\text { barriales } \\
\text { - Conjunto habitacionales } \\
\text { unifamiliares } \\
\text { - Viviendas de interés } \\
\text { social }\end{array}$ & $\begin{array}{l}\text { - Viviendas } \\
\text { multifamiliares } \\
\text { - Industrias de todo } \\
\text { tipo } \\
\text { - Usos no } \\
\text { especificados } \\
\text { como permitidos o } \\
\text { permisibles } \\
\end{array}$ \\
\hline \multirow{3}{*}{ : } & Protección ambiental & $\begin{array}{l}\text { - Recreación y deporte } \\
\text { - Reservas naturales } \\
\text { - Áreas protegidas } \\
\text { - Eco-turismo }\end{array}$ & $\begin{array}{l}\text { - Actividad } \\
\text { agro-ecológica según } \\
\text { aptitud y ubicación } \\
\text { - Servicios compatibles } \\
\text { con los usos permitidos, } \\
\text { sin infraestructuras } \\
\text { permanente (kioscos, } \\
\text { ferias) }\end{array}$ & $\begin{array}{l}\text { - Urbanizaciones o } \\
\text { loteamientos } \\
\text { - Industrias de todo } \\
\text { tipo } \\
\text { - Usos no } \\
\text { especificados } \\
\text { como permitidos o } \\
\text { permisibles }\end{array}$ \\
\hline & Turística/Histórica & $\begin{array}{l}\text { - Turismo: urbano, cultural } \\
\text { y necrófilo }\end{array}$ & $\begin{array}{l}\text { Servicios compatibles } \\
\text { con los usos permitidos, } \\
\text { sin infraestructuras } \\
\text { permanente (kioscos, } \\
\text { ferias) }\end{array}$ & \multirow[t]{2}{*}{$\begin{array}{l}\text { - Usos no } \\
\text { especificados } \\
\text { como permitidos o } \\
\text { permisibles }\end{array}$} \\
\hline & Expansión Urbana & $\begin{array}{l}\text { - Agricultura orgánica } \\
\text { según aptitud de suelo } \\
\text { - Tenencia de aves, } \\
\text { porcinos y vacunos para } \\
\text { autoconsumo } \\
\text { - Equipamiento } \\
\text { comunitario/servicios } \\
\text { pequeña escala } \\
\text { compatible con los usos } \\
\text { permitidos }\end{array}$ & $\begin{array}{l}\text { - Loteamientos cuya trama } \\
\text { vial coincida con la } \\
\text { existente en la zona } \\
\text { urbana } \\
\text { - Equipamiento c } \\
\text { comunitario/servicios } \\
\text { mediante escala } \\
\text { compatible con los usos } \\
\text { permitidos }\end{array}$ & \\
\hline
\end{tabular}


Ovetí (Gluchea divaricata); Timbo; Yvyra Say'ju (Terminalia tiflora). No obstante, se observa que las márgenes de los arroyos que cruzan el casco urbano, están desprovistas de franja de protección, causando menor permeabilidad e incremento de la escorrentía, razón por la cual en la zona alta del arroyo Mboreví (localidad Cerrito) se observó la formación de cárcavas y erosión del suelo.

De acuerdo al análisis del medio físico artificial, el uso habitacional, servicios y comercio ocupa 117.91 ha representando al $38.61 \%$ de la superficie, se localizan en los seis barrios. El uso agrícola, ganadero, forestal, ocupa $14.18 \mathrm{ha} ; 4.63 \%$ de la superficie total, al noreste del casco urbano, anexado a la ciudad, con monocultivo de caña de azúcar. El uso destinado a área verde y espacio abierto ocupa 133.70ha, $43.66 \%$ del total; el uso correspondiente a equipamiento conformado por los edificios e instalaciones destinados a cubrir las necesidades básicas de los habitantes, ocupa unas $18.50 \mathrm{ha}, 6.51 \%$ de la superficie total y el uso destinado a recreación y amenidades ocupa 21.91 ha, $7.16 \%$ de la superficie total. Ambos están distribuidos en toda el área de estudio.

$\mathrm{La}$ infraestructura de red eléctrica existe en todos los barrios del casco urbano de estudio, la misma es provista por la Administración Nacional de Electricidad (ANDE) del complejo de Acaray; la red de drenaje, tiene reducido nivel de entubamiento; la distribución de agua potable, existe en la comuna mediante la junta de saneamiento con sus cincos pozos profundos; y la red de telecomunicaciones, posee dos antenas de servicio de telefonía celular ubicada en las cercanías al barrio San Blás I (claro y personal) más una central telefónica de la Compañía Paraguaya de Comunicaciones (COPACO), ubicada en barrio centro. Además posee una estación de televisión por cable de nombre Cable Visión Piribebuy.

En cuanto a la vialidad y transporte, la ruta a Paraguarí, es el eje principal de alcance regional que recorre de norte a sur el territorio municipal. El $16.58 \%$ de las calles del casco urbano están asfaltadas. El $32.55 \%$ de las calles corresponden a la categoría de empedrados, y el $50.87 \%$ de las calles son caminos de tierra.

En relación a área verde y espacio abierto, espacios públicos abiertos, se localizan dentro de los barrios: María Auxiliadora, Centro, San Blás II y Virgen del Rosario, bajo un patrón de dispersión, áreas fragmentadas inmersas dentro de la mancha urbana usada como recreativas; cuentan con intención de diseño, la mayoría carecen de mantenimiento. Terrenos baldíos se localizan en todos los barrios. De carácter agrícola sólo se encontraron en dos sitios (barrio Santa Ana). Parques-equipamiento recreativo se localizan en el barrio Centro y Santa Ana, y la correspondiente a carácter deportivo recreativo, cuentan con mantenimiento.

Dentro del análisis del medio social, en sus aspectos demográficos, se observa que la población del casco urbano consta de 9,650 habitantes (7,397 habitantes en el 
censo anterior), siendo 4,750 varones y 4,900 mujeres (DGEEC, 2010). ${ }^{10}$ Posee crecimiento lento, pero en la estación veraniega recibe importante número de turistas. No posee infraestructura adecuada capaz de albergar y brindar opciones de recreación. Entre las actividades económicas, ofrece trabajo mayormente en la docencia, entes estatales y/o municipales, también posee centros comerciales en su territorio o cercanos al municipio. Un importante porcentaje de la población joven migró, en busca de oportunidades laborales o para proseguir con sus estudios. Los destinos más comunes son Asunción, Argentina, España y Canadá.

El turismo se basa en visitas a los lugares históricos y naturales como el templo "Dulce Nombre de Jesús" en cuya plaza se libró la épica Batalla de Piribebuy, el 12 de agosto de 1869, el museo histórico Pedro Pablo Caballero, que guarda en su interior reliquias de la guerra del 70 y de la guerra del Chaco. Balnearios como Pinamar, Jardines de Pirareta, Costa Verde, La Palmera, Paso Jhú, Syry, El Bosque, Paraíso Escondido, Salto Amambay, entre otros; los cuales cuentan con lugares para camping. En la ciudad funcionan dos hoteles y algunas pensiones. En la compañía Chololó se tiene además un parador turístico.

La propuesta de zonificación (Figura 2) se ha realizado en base al uso del suelo actual, a la densidad de urbanización y a los servicios existentes. Se incorporan a la propuesta, las zonas de interés ambiental, protección ambiental, turística/histórica y de expansión urbana. Véase en el Cuadro 1 se detalla las actividades y/o usos permitidos, permisibles y no permitidos que podrán desarrollarse según la zonificación propuesta.

\section{Conclusión}

Se identificaron dos zonas; la primera corresponde a la llamada zona urbana (central, urbanizada y periférica) y la segunda, denominada áreas complementarias (interés ambiental, protección ambiental, turística/histórica y expansión urbana), todas con sus correspondientes reglamentaciones referentes a usos permitidos, permisibles y no permitidos, a fin de evitar que el casco urbano pierda las características que la hacen peculiar.

10 Dirección General de Estadísticas; Encuestas y Censos, "Indicadores por Distritos", 2002. Disponible en <http://www.dgeec.gov.py/>, consultado 15 de septiembre de 2010. 